\title{
EFFECT OF SODIUM DIPROPYLACETATE ON CONFLICT BEHAVIOR IN RATS
}

\author{
Kenji OHMORI, Sadayoshi YAMANAMI, Katsuichi SHUTO \\ and Hirofuto MARUMO \\ Pharmaceuticals Research Laboratory, Kyowa Hakko Kogyo, Co., Ltd. \\ 1188 Nagaizumicho, Shizuoka 411, Japan
}

Accepted July 16, 1980

Sodium dipropylacetate (DPA), a branched chain carboxylic acid, was shown to possess anticonvulsant activities both in clinical and experimentally-induced seizures $(1,2)$. Recently, the effectiveness of DPA in selected neurotic conditions has been evaluated, and this drug was found to be effective for treatment patients with symptoms of obsessive worry and irritable depression $(3,4)$. Since improvement in certain forms of anxiety was reported, it was of interest to study this drug using laboratory procedures. Conflict behavior as devised by Geller and Seifter (5) appears to be one of the most useful tests to study antianxiety drugs. In this test, benzodiazepines, meprobamate and several barbiturates characteristically attenuate suppression produced by punishment, while major tranquilizers and opiates were found to be inactive (6). In the present study, the effect of DPA was compared with that of diazepam and diphenylhydantoin, in a conflict behavior test.

Eight male Wistar rats weighing 350 to $400 \mathrm{~g}$ at the start of the experiment were housed in community cages, and the original body weight was reduced to $80 \%$ by limited feedings. Cages were located in a room maintained at $24 \pm 2{ }^{\circ} \mathrm{C}$ with a relative humidity of $55 \%$, and an artificial day-night cycle $(12 / 12 \mathrm{hr})$ was produced by electric lighting. The rats used in the conflict behavior test had been trained to this technique. The animals had learned to avoid pressing the lever when the light was on in the conditioning chamber (GrasonStadlers, model 1101), as each lever pressing was rewared with milk but at the same time given an electric shock to the feet (DC constant current of $0.5-1.2 \mathrm{~mA}, 0.1 \mathrm{sec}$ of duration). The conflict schedule of $3 \mathrm{~min}$ duration was alternated with a variable interval schedule (VI 2) for $12 \mathrm{~min}$. Each component was repeated 3 times. The rats were all 'drug sophisticated', that is, they had been dosed previously with various benzodiazepine derivatives on a weekly bases for several months. Each test session continued for two successive days. On the first day, the animals were treated with the vehicle 20 min before being placed in the chamber, then their behavior and the rate of lever pressing were recorded for $45 \mathrm{~min}$. On the second day, the same procedure was repeated replacing the vehicle by a drug. Test sessions were spaced at least 1 week apart. Student's $t$-test was employed to determine the statistical significance of the data obtained.

The effects of DPA, diazepam and diphenylhydantoin on responses in both the punished and VI 2 components of the multiple schedule are shown in Fig. 1. DPA in doses between 50 and $400 \mathrm{mg} / \mathrm{kg}$ p.o. increased the response rate suppressed by punishment, while only 

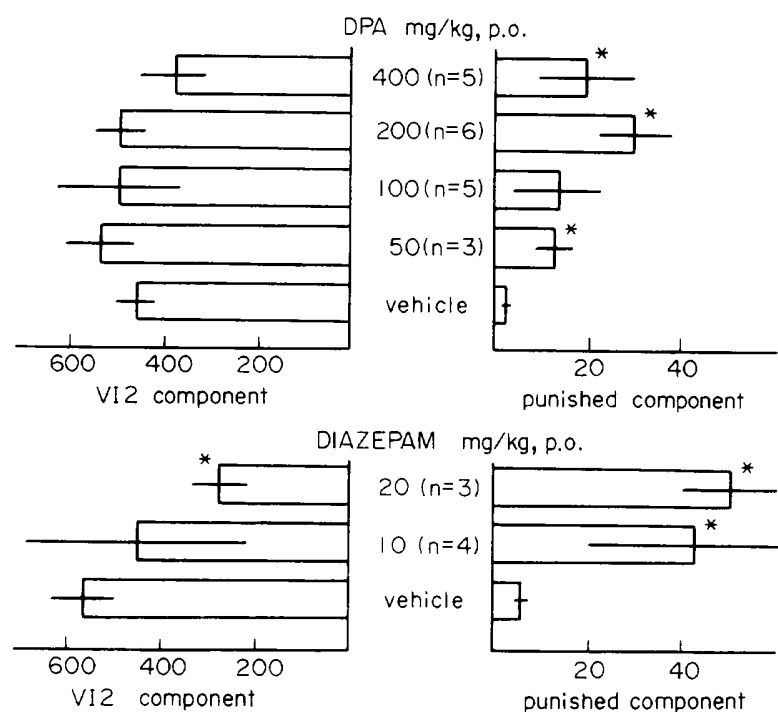

DIAZEPAM $\mathrm{mg} / \mathrm{kg}$, p.o.

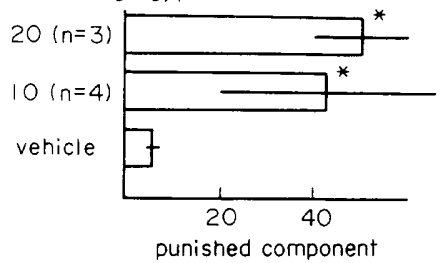

DIPHENYLHYDANTOIN $\mathrm{mg} / \mathrm{kg}, \mathrm{p} .0$.

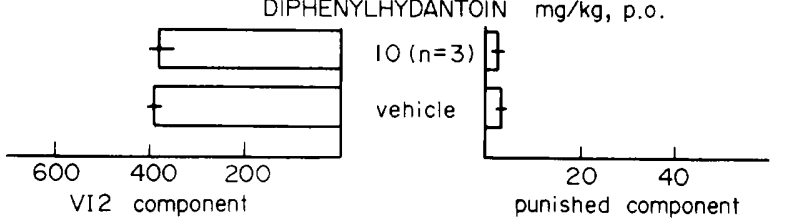

FIG. I. Effects of dipropylacetate (DPA), diazepam and diphenylhydantoin on responses in both the punished and VI 2 components of the multiple schedule. Each column shows the mean, and the horizontal lines show S.E., $n=$ number of determinations. Statistically different from the corresponding vehicle treated rats; ${ }^{*}, \mathrm{p}<0.02$.

the highest dose of DPA decreased the response rate in VI 2 component. Diazepam in doses of 10 and $20 \mathrm{mg} / \mathrm{kg}$ p.o. increased the response rate in the punished component and decreased the response rate in VI 2 component by 18 and $50 \%$, respectively. In contrast with DPA and diazepam, diphenylhydantoin in a dose of $10 \mathrm{mg} / \mathrm{kg}$ had no effect on the response rate in either the punished or the VI 2 component.

These findings indicate that DPA has an anticonflict effect, similar to that seen with diazepam. In previously obtained data, the ED50 values of DPA, diazepam and diphenylhydantoin in inhibition of maximal electroshock convulsive test in rats were 345, 12 and $18 \mathrm{mg} / \mathrm{kg}$ p.o., respectively (2). Therefore, the doses at which DPA and diazepam showed an anticonflict effect were the same as the doses at which these drugs showed an anticonvulsive effect. Goldberg and Ciofalo (7) demonstrated that diphenylhydantoin in doses of 7.5 and $15 \mathrm{mg} / \mathrm{kg}$ i.p. was ineffective on punished response. Concerning the mechanism of action, it was reported that DPA elevated the GABA levels in the cerebral cortex by inhibiting the degradative enzyme for GABA, GABA transaminase $(1,8)$. Lust et al. (9) showed that the level of cerebellar cyclic GMP was decreased to less than $40 \%$ of control values, whereas that of cyclic AMP was unaffected. On the other hand, there have been many reports that diazepam may act on regulatory GABAnergic neurons (10-12). Thus, DPA and diazepam 
may differ regarding the site of action (13), but they share at least one common effect, namely the change in GABAnergic neuronal activity. The direct mechanism by which DPA attenuates the conflict behavior is now being investigated.

Acknowledgements: We are grateful to Prof. S. Ueki and Dr. Y. Kataoka, Pharmaceutical Sciences, Kyushu University, for pertinent suggestions.

\section{REFERENCES}

1) Simler, S., Ciesielski, L., Maitre, M., Randrianarisoa, H. and Mandel, P.: Effect of sodium $\mathrm{n}$-dipropylacetate on audiogenic seizures and brain gamma-amino butyric acid level. Biochem. Pharmacol. 22, 1701-1708 (1973)

2) Shuto, K. AND Nishigaki, T.: The pharmacological studies on sodium dipropylacetate, anticonvulsant activities and general pharmacological actions. Pharmacometrics 4, 937-949 (1970)

3) Salzarulo, P. and Lairy, G.C.: EEG and clinical study of Depakin (sodium valproate) in patients with epileptic seizure and/or mental disturbances. EEG Clin. Neurophysiol. 41, 329 (1976)

4) Sommerbeck, K.W., Theilgaard, A., Rasmussen, K.F., Lohren, L., Gram, L. and Wulff, K.: Valproate sodium; evaluation of so-called psychotropic effect. Epilepsia 18, 159-167 (1977)

5) Geller, I. And Seifter, J.: The effects of meprobamate, barbiturate, d-amphetamine and promazine in experimentally induced conflict in the rat. Psychopharmacologia (Berl.) 1, 482-492 (1960)

6) Geller, I., Bachman, E. and Seifter, J.: Effects of reserpine and morphine on behavior suppressed by punishment. Life Sci. 4, 226-231 (1963)

7) Goldberg, M.E. and Ciofalo, V.B.: Effect of diphenylhydantoin sodium and chlordiazepoxide alone and in combination on punishment behavior. Psychopharmacologia (Berl.) 14, 233-239 (1969)

8) Kunino, K. AND Deguchi, T.: Effects of sodium dipropylacetate on $\gamma$-aminobutyric acid and biogenic amines in rat brain. Chem. Pharm. Bull. 25, 2257-2262 (1977)

9) Lust, W.D., Kupferberg, H.J., Passonneau, J.V. And Pentry, J.K.: On the Mechanism of Sodium Valproate; the relationship of GABA and cyclic GMP levels to anticonvulsant activity, clinical and pharmacological aspects of sodium valproate (Epilim) in the treatment of epilepsy, Edited by LeGG, N.J., p. 123-129 MCS Consultants, Tunbridge Wells, England (1975)

10) Costa, E., Guidotti, A. ANd Suria, A.: New concepts on the mechanism of action of benzodiazepines. Life Sci. 17, 167-186 (1975)

11) Geller, H.M., TAylor, D.A. and Hoffer, B.J.: Benzodiazepines and central inhibitory mechanism. Naunyn-Schmiedeberg's Arch. Pharmacol. 304, 81-88 (1978)

12) Mao, C.C., Guidotti, A. ANd Costa, E.: Inhibition by diazepam of the tremor and the increase of cerebellar cGMP content elicited by harmaline. Brain Res. 83, 516-519 (1975)

13) Ueki, S., Araki, Y. and Watanabe, S.: Changes in sensitivity of mice to anticonvulsant drugs following bilateral olfactory bulb ablations. Japan. J. Pharmacol. 27, 183-192 (1977) 